\title{
Housing Demand in Turkey: Application of Grey Forecasting Model
}

\author{
*Abdulkerim Karaaslan \\ Department of Econometrics, Atatürk University, Erzurum Turkey; akkaraaslan@atauni.edu.tr \\ Kürşat Özgür Özden
}

Department of Econometrics, Atatürk University, Erzurum Turkey; kursat.ozden@hotmail.com

Doi:10.5901/mjss.2016.v7n2p52

\section{Abstract}

One of the physiological needs of people is housing. The housing market is the market that meets this need and has a special place in the national economy. "Multiplier - accelerating" effect owned by housing sector, "economic - social" it includes and the experience of the global crisis in 2008 has made the sector the locomotive of economic development. Any movement formed in the housing sector identified as the driving force of economic growth also affects other sectors in a positive way. That being influenced of financial stability by housing sector both in direct and indirect way also took place among the reasons of global crisis in this sense and it is in a quality that may pose systemic risk require being monitored of supply demand indicators related to the system and making predictions for the future. In Turkey that is among the fastest growing economies in the world in recent years, housing sector showed quite strong performance. By making 1.165 .381 house sales in Turkey in 2014 with an increase of $0.7 \%$ compared to the previous year, it was reached to the historical levels, while there was an increase of $173 \%$ in house sales between the years of 2008-2014. In this study, by using the house sales data in Turkey between the years of 2008-2014 in Turkey with Grey Forecasting model and Grey Verhulst model, it was made predictions for the future and these values were compared with actual data.

Keywords: Housing sales, forecasting, grey system theory, grey forecasting, grey Verhulst model.

\section{Introduction}

Housing production is one of the oldest producing fields in the history of mankind. Housing that is one of the most fundamental rights of people is not only a shelter but also a source of security for individuals and families in the community, an investment tool and a building block in the formation of living environment. Housing need of people is met by houses that are economic goods and it cannot be replaced with any other object. These features of housing that are different from the other goods affects the process of markets, so housing market is assumed to be different from the other markets.

Housing sector with the scope of labor intensive industries and with the structure which largely receives input from sub-industries and the related sub-sectors are among the most important dynamics of the national economies. Sector takes over the duty of leverage mostly with the value added it creates and the structure that keeps the economy vibrant, the feature of stimulating more than two hundred sub-sectors.

The requirement of close monitoring the developments of housing markets having dynamic features due to its structure and which have a strong relationship with economic activity has come to the agenda with the last global crisis experienced. Housing market containing systemic risks is affected directly by the macro and micro economic conditions, and has become one of the sectors feeling the changes to occur in the relevant conditions. Following closely the supply and demand indicators in housing market requiring a longer assessment period compared to the other sectors in terms of making both production and consumption decision is one of the most important subjects. Making predictions in order to make a proper analysis for "sensitivity" and "trends" in terms of supply and demand are predictions for the future to make a proper analysis becomes necessary for a sector in which such dynamics and movement will create a domino effect in the economies.

One of the sectors contributing to economic growth in Turkey that is one of the world's fastest-growing economies in recent years is undoubtedly the housing sector. Although the great earthquake disaster occurred in 1999 in Turkey and then the economic crisis experienced in 2000 -2001 years caused postponement in housing demand, it is seen that the sector has slumped into a major process of change since 2005 with structural reforms and transmission programs. But in 
2008, the global financial crisis that took the whole world under the influence and resulted from the housing loans in the US (mortgage) caused a significant contraction in the housing sector and increases the sensitivity on these sectors. With the experience of global crisis, while a decline was being experienced in demand for housing in Turkey in 2008 and 2009, housing demand has pursued a balanced growth in demand since 2010. While it was being reached to the historical levels with 1.165 .381 house sales with an increase of $0.7 \%$ compared to the previous year in Turkey, an increase of $173 \%$ in house sales was observed between the years of 2008-2014.

The purpose of this study is to make predictions by using house sales data in ten provinces where house sales occurred most intensively and in all provinces in Turkey between 2008-2014 with Grey forecasting model (GM) and Grey Verhulst Model (GVM) and indicating whether these predictions are reliable models or not by comparing these predictions with the values occurred and in this context, it is the realization of house sales forecasts covering the years of 2015-2018. Grey System Theory was developed as an alternative theory for the quantification of the uncertainty in the early 1980s by Deng Ji-Long. The basic idea of the emergence of the theory is to predict the behaviors of uncertain systems that cannot be overcome with stochastic or fuzzy models with the help of a limited number of data. Grey forecast is an alternative prediction model in order to make forward predictions in weak data sets that are not complex, chaotic and imprecise. The model is different from the other prediction models with requiring a small number of data and high forecasting reliability and it is more useful compared to intuitive models such as artificial intelligence and fuzzy logic.

Grey forecasting model (GM) has been successfully applied over the last thirty years from the first day it raised until now in many sectors especially social, economic and industrial systems. In scientific literature about the model, it is seen to be applied in many sectors. Hsu (2003) indicated in his study comparing grey forecasting model to conventional models that grey model gave better results for the short-term forecasts in demand forecast for integrated circuit systems. In their study, Yao et al. (2003) developed a grey-based adaptive forecasting model for forecasting the electricity demand for very short terms. As a result, in businesses consuming high energy, they obtained a result protecting transaction costs. Akay and Atak (2007) indicated in their study in which they used electricity demand data in Turkey between 1970 2004 how healthy forecasts were made in the field of energy by the model. Kung and Chang (2003) made forecasts about sales by using the data between 1995 - 2001 in their study where they used grey forecasting model for China automotive industry. Kayacan et al. (2010) analyzed Euro and Dollar parity to cover the years 2005-2007 with grey-based system. Askari and Askari (2011) indicated in their study where they used grey forecasting model to estimate gold prices that the model gave successful results. In his study where he used the sales figures of a drug company, Wang (2007) made estimations by using grey forecasting model as well as grey Verhulst model and he compared the results of both models. In their study, Wang et al. (2007) developed a new model for grey Verhulst model and applied this model on traffic in the port motorway. In their study where they used phone subscription types and numbers as data, Kordnoori et al (2014) made estimations by using grey forecasting model, grey Verhulst model and grey Markov model of estimates in the study used the results in the comparison of the models they used. With a different study conducted by Wang et al. (2012), grey forecasting system has been proposed constituting early warning of food security. When it is examined in terms of scientific literature, it is possible to examine the studies done in the theory of grey system under six main headings as grey production, grey relational analysis, grey modeling, grey forecast, grey decision-making and grey control.

In this study, house sales data until 2018 in Turkey was estimated by using house sales data in all provinces in Turkey between 2008-2014 and in ten provinces where house sales took place most intensively with the grey forecasting model (GM). In the continuation of the study, grey forecasting model is described in detail in Chapter 2. In the 3rd section of the study, grey Verhulst (GVM) and new grey Verhulst (NGVM) of the estimation models within grey system theory have been examined. In the 4th part of the study, the data between 2008 - 2014 were estimated with GM, GVM and NGVM models and the relative errors was calculated and comparisons among the models were made by testing their reliability. In the 5th and last section of the study, the results obtained were evaluated and it was focused on the work to be developed prospectively.

\section{Grey Forecasting Model (GM)}

The grey system theory developed by Deng Ji-Long in the early 1980s as an interdisciplinary approach, focuses on uncertain, inadequate and incomplete data sets to analyze and understand the systems through condition analysis, forecasting and decision-making. Here, light colors refer to clarity and dark colors refer to the uncertainty. While black is expressing to have no knowledge about system characteristics and parameter, white means to access all the information about the system. Between black and white "grey", expressed as color indicate completely unspecified systems. Also in real life, it is made decisions under inadequate and incomplete information assumptions called as the main features of 
GM. GM uses this part of grey system theory that is a basis.

Probability and statistics, fuzzy mathematics and grey system theory are the most common models used in studies for non-deterministic system. Different from the other two different theories, grey system theory was developed to find solution to the problems having small sample size and where poor information is located. The following table shows the differences between the three theories as summary.

Table 1. The comparison of the models that are not deterministic

\begin{tabular}{|l|l|l|l|}
\cline { 2 - 4 } \multicolumn{1}{c|}{} & Grey System Theory & Probability \& Statistics & Fuzzy Mathematics \\
\hline Objects of Study & Poor information Uncertainty & Stochastic Uncertainty & Cognitive Uncertainty \\
\hline Basic Sets & Grey hazy sets & Cantor sets & Fuzzy sets \\
\hline Methods & Information coverage & Probability distribution & Function of affiliation \\
\hline Procedure & Grey series generation & Frequency distribution & Mariginal sample \\
\hline Requirement & Any distribution & Typical distribution & Experience \\
\hline Objective & Laws of reality & Laws of statistics & Cognitive expression \\
\hline Characteristics & Small samples & Large samples & Experience \\
\hline
\end{tabular}

On the other hand, the basic features of grey forecasting model that is one of the main field of occupation differ from traditional forecasting models is the requirement of the limited number of data in order to predict the behaviors of the uncertain system. Traditional forecasting models such as time series need large amount of past period data and known statistical distribution.

On the contrary to the traditional forecasting models, the basic feature of grey forecasting model is that it does not require strict assumptions about data set and it can be applied successfully in the analysis of the systems having limited data. The following table shows the comparison of traditional forecasting models.

Table 2. The comparison of traditional forecasting methods

\begin{tabular}{|l|c|c|c|c|}
\hline Forecasting Method & Required Min. Observation Number & Sample Type & Sample Range & Mathematical Necessity \\
\hline Simple Involutory Functions & $5-10$ & Range & Short & Basic \\
\hline Regression Analysis & $10-20$ & Trend & Short & Middle \\
\hline Random Regression & 10 & Any & Long & Developed \\
\hline Grey Forecasting Model & 4 & Range & Long & Basic \\
\hline
\end{tabular}

GM uses a cumulative model to create differential equations and requires little data. GM $(1,1)$ that is first-degree univariate model used commonly in literature within the scope of the study was used; GM $(1,1)$ is a time-series having varying coefficients in time and hosting a group of differentiable equality. GM $(1,1)$ is defined as follows.

Assume that $x^{(0)}$ Original time series with $\mathrm{n}$ sample number.

$x^{(0)}=\left(x^{0}(1), x^{(0)}(2), x^{(0)}(3), \ldots, x^{(0)}(n)\right)$

Accumulated generating operator (AGO) turns $x^{(0)}$ series continuing as chaotic increasing monotonously into following $x^{(1)}$ series.

$x^{(1)}=\left(x^{(1)}(1), x^{(1)}(2), x^{(1)}(3), \ldots, x^{(1)}(n)\right)$

$x^{(1)}=\left(\sum_{k=1}^{1} x^{(0)}(k), \sum_{k=1}^{2} x^{(0)}(k), \ldots, \sum_{k=1}^{n} x^{(0)}(k)\right)$

In order to reshape GM $(1,1)$ and calculate coefficients, first degree grey differential equality is applied by using $x^{(0)}$ and $x^{(1)}$ series.

$x^{(0)}(k)+a z^{(1)}(k)=b, \quad k=2,3, \ldots, n$

Forming state for GM $(1,1)$ is obtained as follows.

$z^{(1)}=0.5 x^{(1)}(k)+0.5 x^{(1)}(k-1)$

In equity (3), $k$; is described as time points, $a$; is as development coefficient and $b$; is as drive coefficient.

The least squares method over equity (2) and (3) is used and $\hat{a}$ coefficient is obtained.

$\hat{a}=\left[\begin{array}{l}a \\ b\end{array}\right]=\left(B^{T} B\right)^{-1} B^{T} Y_{N}$ 
$B=\left[\begin{array}{cc}-z_{1}^{(1)}(2) & 1 \\ -z_{1}^{(1)}(3) & 1 \\ \vdots & \vdots \\ -z_{1}^{(1)}(n) & 1\end{array}\right]$ and $Y_{N}=\left[\begin{array}{c}x^{(0)}(2) \\ x^{(0)}(3) \\ \vdots \\ x^{(0)}(n)\end{array}\right]$

In order to find the solution of $x^{(1)}$ in equity (3), the following differential equity is used.

$\frac{d x^{(1)}}{d t}+a x^{(1)}=b$

According to the predicted $a$ and $b$ coefficient, with placing $\hat{a}$ coefficient in equity (5), is obtained with GM as a result of first degree differentiable equity that is solved.

$$
\hat{x}^{(1)}(k+1)=\left[x^{(0)}(1)-\frac{b}{a}\right] e^{-a k}+\frac{b}{a}
$$

So, $\hat{x}(k)$ indicates the prediction at $k$ time point of $x$ and it is $x^{(1)}(1)=x^{(0)}(1) . \hat{x}^{(0)}(k)$ is obtained by Inverse Accumulated generating operator (IAGO) on $\hat{x}^{(1)}(k+1)$.

$$
\begin{aligned}
& \hat{x}^{(0)}(k)=\hat{x}^{(1)}(k)-\hat{x}^{(1)}(k-1) \\
& \hat{x}^{(0)}(k)=\left[x^{(0)}(1)-\frac{b}{a}\right] e^{-a(k-1)}\left(1-e^{a}\right)
\end{aligned}
$$

In GM $(1,1)$, all data set is used to make forecast. In case of having chaotic data using the data of recent period is suggested for increasing the forecasting accuracy. In $\mathrm{GM} x^{(0)}(k+1)$, as far as $\mathrm{k}<\mathrm{n}$ in $\mathrm{GM}(1,1)$ forecast is made by applying to $x^{(0)}=\left(x^{(0)}(1), x^{(0)}(2), \ldots, x^{(0)}(k)\right)$ data. After result is found $x^{(0)}(k+1)$ is added to the end of data and at the same time oldest data is removed from data set and operation is repeated. Forecast value of the next period $x^{(0)}=$ $\left(x^{(0)}(2), x^{(0)}(3), \ldots, x^{(0)}(k+1)\right)$ is used to forecast $x^{(0)}(k+2)$ value.

In order to measure the efficiency of GM $(1,1)$, mean absolute percentage error (MAPE) values are calculated by comparing the realized and forecasted values.

$$
e(k)=\left|\frac{x^{(0)}(k)-\hat{x}^{(0)}(k)}{x^{(0)}(k)}\right| 100 \%, \quad k=2,3, \ldots, n
$$

The efficiency of MAPE values, expressing the average of sum of absolute values of percentage errors, in forecasts obtained by GM $(1,1)$ are shown in below table.

Table 3. Comparison of MAPE value efficiencies in forecasts

\begin{tabular}{|c|l|}
\hline MAPE (\%) & Forecast power \\
\hline$>50$ & Weak and inaccurate forecasting \\
\hline $20-50$ & Reasonable forecasting \\
\hline $10-20$ & Good forecasting \\
\hline$<10$ & Highly accurate forecasting \\
\hline
\end{tabular}

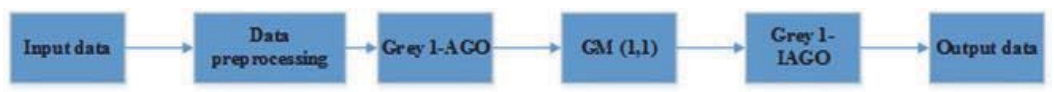

Figure 1. The forecast system based on GM $(1,1)$

\section{Grey Verhulst Model (GVM)}

Verhulst model was initially proposed by German mathematician - biologist Pierre Francois Verhulst in 1837. The main aim of the model is to limit all development for a real system. This non-linear model are effective in defining many increasing processes having saturation region or such as S shaped curve. GVM which is handled as a forecast model within grey system theory, anticipates that original data and raw data should be in S shaped curve form in order not to obtain weak forecast results. GVM is defined as below.

Let $n$ be sample quantity and $x^{(0)}$ be original time series

$x^{(0)}=\left(x^{0}(1), x^{(0)}(2), x^{(0)}(3), \ldots, x^{(0)}(n)\right)$

Let $n$ be sample quantity and $x^{(1)}$ be raw time series

$x^{(1)}=\left(x^{(1)}(1), x^{(1)}(2), x^{(1)}(3), \ldots, x^{(1)}(n)\right)$

Accumulated generating operator (AGO), converts chaotically continuing $x^{(0)}$ series to the monotonously increasing $z^{(1)}$ series below.

$$
x^{(1)}(k)=\sum_{i=1}^{k} x^{(0)}(i), k=1,2, \ldots, n
$$


$z^{(1)}=\left(z^{(1)}(1), z^{(1)}(2), z^{(1)}(3), \ldots, z^{(1)}(n)\right)$

The series belonging to the consecutive neighbours of $x^{(1)}$ series and configurated form is obtained as below.

$z^{(1)}(k)=\frac{1}{2}\left(x^{(1)}(k)+x^{(1)}(k-1)\right), \quad k=2,3, \ldots, n$

In order to find the solution of $x^{(1)}$ below differential equation is used.

$\frac{d x^{(1)}}{d t}+a x^{(1)}=b\left(x^{(1)}\right)^{2}$

$x^{(0)}(k)+a z^{(1)}(k)=b\left(z^{(1)}(k)\right)^{a}$

In equation (13) similar to $\mathrm{GM}(1,1), k$ is defined as time dots, $a$ is defined as development coefficient and $b$ is defined as driver coefficient. Through equation (10) and (13) $\hat{a}$ coefficient is obtained by using least squares method similar to $\mathrm{GM}(1,1)$.

$$
\begin{aligned}
\hat{a} & =\left[\begin{array}{l}
a \\
b
\end{array}\right]=\left(B^{T} B\right)^{-1} B^{T} Y_{N} \\
B & =\left[\begin{array}{cc}
-z_{1}^{(1)}(2) & \left(z^{(1)}(2)\right)^{2} \\
-z_{1}^{(1)}(3) & \left(z^{(1)}(3)\right)^{2} \\
\vdots & \vdots \\
-z_{1}^{(1)}(n) & \left(z^{(1)}(n)\right)^{2}
\end{array}\right] \text { and } Y_{N}=\left[\begin{array}{c}
x^{(1)}(2) \\
x^{(1)}(3) \\
\vdots \\
x^{(1)}(n)
\end{array}\right]
\end{aligned}
$$

As a result of solution of $x^{(1)}(t)$ for $k$ time, GVM is obtained.

$\hat{x}^{(1)}(k+1)=\frac{a x^{(0)}(1)}{b x^{(0)}(1)+\left(a-b x^{(0)}(1)\right) e^{a k}}$

Mean absolute percentage error (MAPE) obtained as a result of GVM is calculated by the formula below.

$\Delta_{k}=\frac{\left|\varepsilon^{(1)}(k)\right|}{x^{(1)}(k)}, \quad \varepsilon^{(1)}(k)=x^{(1)}(k)-\hat{x}^{(1)}(k)$

As seen in equation (16) if $a<0, \lim _{k \rightarrow \infty} x^{(1)}(k) \rightarrow \frac{a}{b}$, and at the same time if $a>0 \lim _{k \rightarrow \infty} x^{(1)}(k) \rightarrow 0$. This expression means the saturation point in equation (16) where the value limiting the forecast value is $\frac{a}{b}$. This expression at the same time means that when " $k$ " is great enough $x^{(1)}(k)$ and $x^{(1)}(k+1)$ values will be very close. Due to this property, GVM is widely used in definition and forecasting of processes with saturation region.

Although GVM was initially proposed for modeling a living creature population in a limited area but it is also widely used in forecasting statistical and econometric models. However as statistical and econometric modellings are made with big samples an increasing GVM in S shaped curve form and suggesting usage of small samples had to be developed. In line of this requirement Wang et al. developed a new model for grey Verhulst model in a study they performed in 2007 and named it as "New Grey Verhulst Model (NGVM)". NGVM aims to use trapezoid formula instead of difference model and differential equations for forecasting $\hat{a}$ coefficient in order to increase the accuracy of forecast. NGVM is defined as follows.

Let $n$ be sample quantity and $x^{(0)}$ be original time series

$x^{(0)}=\left(x^{0}(1), x^{(0)}(2), x^{(0)}(3), \ldots, x^{(0)}(n)\right)$

Let $n$ be sample quantity and $x^{(1)}$ be raw time series

$x^{(1)}=\left(x^{(1)}(1), x^{(1)}(2), x^{(1)}(3), \ldots, x^{(1)}(n)\right)$

The stages in GVM (10) - (14) are followed similarly and $\hat{a}$ coefficient is obtained. However formulation is differentiated during obtaining stage of $B$ matrix.

$$
\begin{aligned}
& \hat{a}=\left[\begin{array}{l}
a \\
b
\end{array}\right]=\left(B^{T} B\right)^{-1} B^{T} Y_{N} \\
& B=\left[\begin{array}{cc}
-\frac{1}{2}\left[x^{(1)}(1)+x^{(1)}(2)\right] & \frac{1}{2}\left[\left(x^{(1)}(1)\right)^{2}+\left(x^{(1)}(2)\right)^{2}\right] \\
-\frac{1}{2}\left[x^{(1)}(2)+x^{(1)}(3)\right] & \frac{1}{2}\left[\left(x^{(1)}(2)\right)^{2}+\left(x^{(1)}(3)\right)^{2}\right] \\
\vdots & \vdots \\
-\frac{1}{2}\left[x^{(1)}(n-1)+x^{(1)}(n)\right] & \frac{1}{2}\left[\left(x^{(1)}(n-1)\right)^{2}+\left(x^{(1)}(n)\right)^{2}\right]
\end{array}\right] \quad Y_{N}=\left[\begin{array}{c}
x^{(0)}(2) \\
x^{(0)}(3) \\
\vdots \\
x^{(0)}(n)
\end{array}\right]
\end{aligned}
$$

Similar to GVM, NGVM is obtained as a result of solution of $x^{(1)}(t)$ for $k$ time.

$$
\hat{x}^{(1)}(k+1)=\frac{a x^{(1)}(0)}{b x^{(1)}(0)+\left(a-b x^{(1)}(0)\right) e^{a k}}
$$

As seen in equation (19) if $a<0, \lim _{k \rightarrow \infty} x^{(1)}(k) \rightarrow \frac{a}{b}$, and at the same time if $a>0 \lim _{k \rightarrow \infty} x^{(1)}(k) \rightarrow 0$. This expression means the saturation point in equation (18) where the value limiting the forecast value is $\frac{a}{b}$. The flowchart summarizing the stages in GVM and NGVM are shown below. 


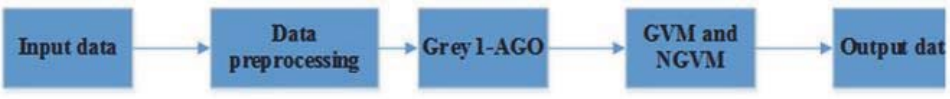

Figure 2. The forecast system based on GVM and NGVM

\section{Forecasting of Housing Demand in Turkey by GM, GVM and NGVM}

The main aim of this study is to forecast the housing demand in Turkey by using GM, GVM and NGVM and compare the mentioned models. All data used under the scope of the study were provided by Turkish statistical institute (TUIK). In the study house sales data in ten provinces of Turkey where house sales activity is most intensive between 2008-2014 were used and in below tables the data between years 2008-2014 were forecasted by GM, GVM and NGVM in order to calculate the mean absolute percentage error (MAPE) values and comparisons between models were made by testing their reliabilities.

Table 4. Actual and forecasted house sales in GM (1,1) (2008-2014)

\begin{tabular}{|c|c|c|c|c|c|c|c|c|c|c|}
\hline & \multirow{2}{*}{\begin{tabular}{|l|} 
Provinces \\
\end{tabular}} & \multicolumn{8}{|c|}{ House Sales Amount } & \multirow[t]{2}{*}{ MAPE (\%) } \\
\hline & & Years & 2008 & 2009 & 2010 & 2011 & 2012 & 2013 & 2014 & \\
\hline \multirow[t]{4}{*}{1} & Ankara & Actual & 87087 & 104285 & 106006 & 117908 & 106019 & 137773 & 131825 & \\
\hline & & Forecasted & 87087 & 101885 & 107590 & 113614 & 119975 & 126692 & 133786 & 5.022 \\
\hline & & $e(k)(\%)$ & 0 & 2.301 & 1.494 & 3.642 & 13.163 & 8.043 & 1.487 & \\
\hline & & $1-e(k)(\%)$ & 0 & 97.699 & 98.506 & 96.358 & 86.837 & 91.957 & 98.513 & \\
\hline \multirow[t]{4}{*}{2} & İstanbul & Actual & 103503 & 140573 & 153897 & 169015 & 167110 & 234789 & 225454 & \\
\hline & & Forecasted & 103503 & 137030 & 152343 & 169367 & 188293 & 209335 & 232728 & 5.080 \\
\hline & & $e(\boldsymbol{k})(\%)$ & 0 & 2.520 & 1.010 & 0.208 & 12.676 & 10.841 & 3.226 & \\
\hline & & $1-e(k)(\%)$ & 0 & 97.480 & 98.990 & 99.792 & 87.324 & 89.159 & 96.774 & \\
\hline \multirow[t]{4}{*}{3} & Izmir & Actual & 26627 & 34828 & 39702 & 44876 & 46429 & 72421 & 71779 & \\
\hline & & Forecasted & 26627 & 33086 & 38878 & 45684 & 53681 & 63080 & 74123 & 6.777 \\
\hline & & $e(k)(\%)$ & 0 & 5.003 & 2.076 & 1.801 & 15.621 & 12.899 & 3.265 & \\
\hline & & $1-\boldsymbol{e}(\boldsymbol{k})(\%)$ & 0 & 94.997 & 97.924 & 98.199 & 84.379 & 87.101 & 96.735 & \\
\hline \multirow[t]{4}{*}{4} & Bursa & Act & 10244 & 14879 & 19966 & 24092 & 24724 & 40894 & 42437 & \\
\hline & & Foreca & 10244 & 15371 & 18965 & 23399 & 28869 & 35618 & 43945 & 7.403 \\
\hline & & $e(\boldsymbol{k})(\%)$ & 0 & 3.309 & 5.014 & 2.878 & 16.765 & 2.902 & 3.553 & \\
\hline & & $1-e(k)(\%)$ & 0 & 96.691 & 94.986 & \begin{tabular}{|l|}
97.122 \\
\end{tabular} & 83.235 & 87.098 & 96.447 & \\
\hline \multirow[t]{4}{*}{5} & Mersin & Actual & 11216 & 13692 & 15141 & \begin{tabular}{|l|}
18464 \\
\end{tabular} & 18447 & 32393 & 31204 & \\
\hline & & Forecasted & 11216 & 12634 & 15729 & \begin{tabular}{|l|}
18477 \\
\end{tabular} & 22345 & 27022 & 32679 & 8.524 \\
\hline & & $e(k)(\%)$ & 0 & 7.724 & 0.912 & 0.072 & 21.131 & 16.579 & 4.727 & \\
\hline & & $1-e(k)(\%)$ & 0 & \begin{tabular}{|l|}
92.276 \\
\end{tabular} & 99.088 & \begin{tabular}{|l|}
99.928 \\
\end{tabular} & 78.869 & 83.421 & 95.273 & \\
\hline \multirow[t]{4}{*}{6} & Antalya & Act & 24821 & \begin{tabular}{|l|}
30602 \\
\end{tabular} & 31419 & 35451 & 34555 & 59478 & 62227 & \\
\hline & & Forecasted & 24821 & 25857 & 30785 & 36652 & 43637 & 51953 & 61855 & 10.074 \\
\hline & & $e(k)(\%)$ & 0 & 15.506 & 2.019 & 3.387 & 26.283 & 12.651 & 0.598 & \\
\hline & & $1-e(k)(\%)$ & 0 & 84.494 & 97.981 & 96.613 & 73.317 & 87.349 & 99.402 & \\
\hline \multirow[t]{4}{*}{7} & Eskişehir & Actual & 9928 & 11077 & 14006 & \begin{tabular}{|l|}
17325 \\
\end{tabular} & 19422 & 21292 & 19921 & \\
\hline & & Forecasted & 9928 & \begin{tabular}{|l|}
12990 \\
\end{tabular} & 14443 & \begin{tabular}{|l|}
16059 \\
\end{tabular} & 17855 & 19852 & 22072 & 8.889 \\
\hline & & $e(k)$ & 0 & 17.274 & 3.122 & 7.310 & 8.070 & 6.765 & 10.796 & \\
\hline & & $1-e(k)(\%)$ & 0 & 82.726 & 96.878 & 92.690 & 91.930 & 93.235 & 89.204 & \\
\hline \multirow[t]{4}{*}{8} & Kayseri & Act & 10615 & 13015 & 15873 & 19040 & 18581 & 27109 & 28375 & \\
\hline & & Forec & 10615 & $\mid 13228$ & 15470 & 18091 & 21156 & 24741 & 28934 & 5.621 \\
\hline & & $e(k)$ & 0 & 1.637 & 2.542 & 4.985 & 13.860 & 8.734 & 1.969 & \\
\hline & & $1-e(k)(\%)$ & U & 98.363 & 97.458 & 95.015 & 86.140 & 91.266 & 98.031 & \\
\hline \multirow[t]{4}{*}{9} & Konya & Actual & 10102 & 13963 & 14434 & 16838 & 17491 & 27724 & 29385 & \\
\hline & & Forecasted & 10102 & 12121 & 14476 & 17287 & 20645 & 24654 & 29442 & 7.574 \\
\hline & & $e(k)(\%)$ & 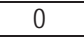 & 13.189 & 0.289 & \begin{tabular}{|l|l|}
2.667 \\
\end{tabular} & 18.030 & 11.073 & 0.196 & \\
\hline & & $1-\boldsymbol{e}(\boldsymbol{k})(\%)$ & 0 & 86.811 & 99.711 & 97.333 & 81.970 & 88.927 & 99.804 & \\
\hline 10 & Adana & Actual & 9981 & 13057 & 14084 & \begin{tabular}{|l|}
17412 \\
\end{tabular} & 15911 & 20928 & 20897 & \\
\hline
\end{tabular}




\begin{tabular}{|l|c|c|c|c|c|c|c|c|c|c|}
\hline & & Forecasted & 9981 & 13171 & 14518 & 16003 & 17640 & 19444 & 21433 & 5.428 \\
\hline & & $\boldsymbol{e}(\boldsymbol{k})(\%)$ & 0 & 0.870 & 3.081 & 8.092 & 10.866 & 7.089 & 2.567 & \\
\hline & & $\mathbf{1 - \boldsymbol { e } ( \boldsymbol { k } ) ( \% )}$ & 0 & 99.130 & 96.919 & 91.908 & 89.134 & 92.911 & 97.433 & \\
\hline $\mathbf{1 1}$ & Turkey & Actual & 427105 & 555184 & 607098 & 708275 & 701621 & 1157190 & 1165381 & \\
\hline & & Forecasted & 427105 & 506381 & 600774 & 712761 & 845624 & 1003253 & 1190265 & 7.738 \\
\hline & & $\boldsymbol{e}(\boldsymbol{k})(\%)$ & 0 & 8.790 & 1.042 & 0.633 & 20.524 & 13.303 & 2.135 & \\
\hline & & $\mathbf{1 - e}(\boldsymbol{k})(\%)$ & 0 & 91.210 & 98.958 & 99.367 & 79.476 & 86.697 & 97.865 & \\
\hline
\end{tabular}

Table 5. Actual and forecasted house sales in GVM original data (2008-2014)

\begin{tabular}{|c|c|c|c|c|c|c|c|c|c|c|}
\hline & \multirow[t]{2}{*}{ Provinces } & \multicolumn{8}{|c|}{ House Sales Amount } & \multirow[t]{2}{*}{ MAPE (\%) } \\
\hline & & Years & 2008 & 2009 & 2010 & 2011 & 2012 & 2013 & 2014 & \\
\hline \multirow[t]{4}{*}{1} & Ankara & Actual & \begin{tabular}{|l|}
87087 \\
\end{tabular} & 104285 & 106006 & 117908 & 106019 & 137773 & 131825 & \\
\hline & & Forecasted & 87087 & 97977 & 107609 & 115756 & 122388 & 127623 & 131654 & 4.618 \\
\hline & & $\varepsilon^{(1)}(k)$ & 0 & 6308 & -1603 & 2152 & -16369 & 10150 & 171 & \\
\hline & & $\Delta_{k}(\%)$ & 0 & 6.049 & 1.512 & 1.826 & 15.440 & 7.367 & 0.129 & \\
\hline \multirow[t]{4}{*}{2} & İstanbul & Actual & 103503 & 140573 & 153897 & 169015 & 167110 & 234789 & \begin{tabular}{|l|}
225454 \\
\end{tabular} & \\
\hline & & Forecasted & 103503 & 126995 & 150888 & 173685 & 194150 & 211538 & \begin{tabular}{|l|}
225636 \\
\end{tabular} & 5.792 \\
\hline & & $\bar{\varepsilon}^{(1)}(k)$ & 0 & 13578 & 3009 & -4670 & -27040 & 23251 & -182 & \\
\hline & & $\Delta_{k}(\%)$ & 0 & 9.659 & 1.955 & 2.763 & 16.181 & 9.903 & 0.081 & \\
\hline \multirow[t]{4}{*}{3} & İmir & Actual & 26627 & 34828 & 39702 & 44876 & 46429 & 72421 & 71779 & \\
\hline & & Forecasted & 26627 & 33359 & 40922 & \begin{tabular}{|l|}
49051 \\
\end{tabular} & 57384 & 65520 & 73096 & 7.365 \\
\hline & & $\varepsilon^{(1)}(k)$ & 0 & 1469 & -1220 & -4175 & -10955 & 6901 & -1317 & \\
\hline & & $\Delta_{k}(\%)$ & 0 & 4.218 & 3.073 & 9.304 & 23.595 & 9.529 & 1.834 & \\
\hline \multirow[t]{4}{*}{4} & Bursa & Actual & 10244 & 14879 & 19966 & 24092 & 24724 & 40894 & 42437 & \\
\hline & & Forecasted & 10244 & 14290 & \begin{tabular}{|l|}
19318 \\
\end{tabular} & 25149 & 31395 & 37539 & 43098 & 6.906 \\
\hline & & $\varepsilon^{(1)}(k)$ & 0 & 589 & 648 & -1057 & -6671 & 3355 & -661 & \\
\hline & & $\Delta_{k}(\%)$ & 0 & 3.960 & 3.247 & 4.389 & 26.983 & 8.203 & 1.557 & \\
\hline \multirow[t]{4}{*}{5} & Mersin & Actual & 11216 & 13692 & 15141 & 18464 & 18447 & 32393 & 31204 & \\
\hline & & Forecasted & 11216 & 14334 & 17879 & 21708 & 25624 & 29408 & 32870 & 13.400 \\
\hline & & $\varepsilon^{(1)}(k)$ & 0 & -642 & -2738 & -3244 & -7177 & 2985 & -1666 & \\
\hline & & $\Delta_{k}(\%)$ & 0 & 4.686 & 18.080 & 17.571 & 38.905 & 9.216 & 5.339 & \\
\hline \multirow[t]{4}{*}{6} & Antalya & Actual & 24821 & 30602 & 31419 & 35451 & 34555 & 59478 & 62227 & \\
\hline & & Forecasted & 24821 & 29627 & 35228 & 41702 & 49116 & 57511 & 66903 & 12.272 \\
\hline & & $\varepsilon^{(1)}(k)$ & 0 & 975 & -3809 & -6251 & -14561 & 1967 & -4676 & \\
\hline & & $\Delta_{k}(\%)$ & 0 & 3.188 & 12.123 & 17.634 & 42.137 & 3.307 & 7.514 & \\
\hline \multirow[t]{4}{*}{7} & Eskişehir & Actual & 9928 & 11077 & 14006 & 17325 & 19422 & 21292 & 19921 & \\
\hline & & Forecasted & 9928 & 12544 & 14997 & 17068 & 18669 & 19823 & 20613 & 5.151 \\
\hline & & $\varepsilon^{(1)}(k)$ & 0 & -1467 & -991 & 257 & 753 & 1469 & -692 & \\
\hline & & $\Delta_{k}(\%)$ & 0 & 13.245 & 7.076 & 1.481 & 3.878 & 6.902 & 3.474 & \\
\hline \multirow[t]{4}{*}{8} & Kayseri & Actual & 10615 & 13015 & 15873 & 19040 & 18581 & 27109 & 28375 & \\
\hline & & Forecasted & 10615 & 13073 & \begin{tabular}{|l|}
15856 \\
\end{tabular} & 18907 & 22136 & 25428 & 28658 & 3.940 \\
\hline & & $\varepsilon^{(1)}(k)$ & 0 & -58 & 17 & 133 & -3555 & 1681 & -283 & \\
\hline & & $\Delta_{k}(\%)$ & 0 & 0.446 & 0.106 & 0.697 & 19.133 & 6.202 & 0.996 & \\
\hline \multirow[t]{4}{*}{9} & Konya & Actual & 10102 & 13963 & 14434 & 16838 & 17491 & 27724 & 29385 & \\
\hline & & Forecasted & 10102 & 12491 & 15294 & 18513 & 22121 & 26055 & 30220 & 8.825 \\
\hline & & $\varepsilon^{(\mathbf{1})}(k)$ & 0 & 1472 & -860 & -1675 & -4630 & 1669 & -835 & \\
\hline & & $\Delta_{k}(\%)$ & 0 & 10.540 & 5.959 & 9.948 & 26.469 & 6.020 & 2.841 & \\
\hline \multirow[t]{4}{*}{10} & Adana & Actual & 9981 & 13057 & 14084 & 17412 & 15911 & 20928 & 20897 & \\
\hline & & Forecasted & 9981 & 12194 & 14392 & 16433 & 18213 & 19681 & 20838 & 5.018 \\
\hline & & $\varepsilon^{(1)}(k)$ & 0 & 863 & -308 & 979 & -2302 & 1247 & 59 & \\
\hline & & $\Delta_{k}(\%)$ & 0 & 6.610 & 2.189 & 5.621 & 14.466 & 5.959 & 0.282 & \\
\hline \multirow[t]{4}{*}{11} & Turkey & Actual & 427105 & 555184 & 607098 & 708275 & 701621 & 1157190 & 1165381 & \\
\hline & & Forecasted & 427105 & 531308 & 650261 & 781440 & 920703 & 1062706 & 1201670 & 9.178 \\
\hline & & $\varepsilon^{(1)}(k)$ & 0 & 23876 & -43163 & -73165 & -219082 & 94484 & -36289 & \\
\hline & & $\Delta_{k}(\%)$ & 0 & 4.301 & 7.110 & 10.330 & 31.225 & 8.165 & 3.114 & \\
\hline
\end{tabular}


Table 6. Actual and forecasted house sales in GVM raw data (2008-2014)

\begin{tabular}{|c|c|c|c|c|c|c|c|c|c|c|}
\hline \multirow{2}{*}{\multicolumn{2}{|c|}{ Provinces }} & \multicolumn{8}{|c|}{ House Sales Amount } & \multirow[t]{2}{*}{ MAPE (\%) } \\
\hline & & Years & 2008 & 2009 & 2010 & 2011 & 2012 & 2013 & 2014 & \\
\hline \multirow[t]{4}{*}{1} & Ankara & Actual & 87087 & 104285 & 106006 & 117908 & 106019 & 137773 & 131825 & \\
\hline & & Forecasted & 87087 & 51640 & 75562 & 102662 & 126273 & 137607 & 131518 & 15.941 \\
\hline & & $\varepsilon^{(0)}(k)$ & 0 & 52645 & 30444 & 15246 & -20254 & 166 & 307 & \\
\hline & & $\Delta_{k}(\%)$ & 0 & 50.482 & 28.719 & 12.930 & 19.104 & 0.120 & 0.233 & \\
\hline \multirow[t]{4}{*}{2} & İstanbul & Actual & 103503 & 140573 & 153897 & 169015 & 167110 & 234789 & 225454 & \\
\hline & & Forecasted & 103503 & 63030 & 95364 & 136372 & 180069 & 214284 & 225583 & 18.436 \\
\hline & & $\varepsilon^{(0)}(k)$ & 0 & 77543 & 58533 & 32643 & -12959 & 20505 & -129 & \\
\hline & & $\Delta_{k}(\%)$ & 0 & 55.162 & 38.034 & 19.314 & 7.755 & 8.733 & 0.057 & \\
\hline \multirow[t]{4}{*}{3} & İzmir & Actual & 26627 & 34828 & 39702 & 44876 & 46429 & 72421 & 71779 & \\
\hline & & Forecasted & 26627 & 15677 & 23797 & 34657 & 47546 & 60147 & 68740 & 20.201 \\
\hline & & $\varepsilon^{(0)}(k)$ & 0 & 19151 & 15905 & 10219 & -1117 & 12274 & 3039 & \\
\hline & & $\Delta_{k}(\%)$ & 0 & 54.987 & 40.061 & 22.771 & 2.406 & 16.949 & 4.234 & \\
\hline \multirow[t]{4}{*}{4} & Bursa & Actual & 10244 & 14879 & 19966 & 24092 & 24724 & 40894 & 42437 & \\
\hline & & Forecasted & 10244 & 6567 & 10415 & 15969 & 23260 & 31467 & 38565 & 25.073 \\
\hline & & $\varepsilon^{(0)}(k)$ & 0 & 8312 & 9551 & 8123 & 1464 & 9427 & 3872 & \\
\hline & & $\Delta_{k}(\%)$ & 0 & 55.865 & 47.837 & 33.716 & 5.920 & 23.053 & 9.123 & \\
\hline \multirow[t]{4}{*}{5} & Mersin & Actual & 11216 & 13692 & 15141 & 18464 & 18447 & 32393 & 31204 & \\
\hline & & Forecasted & 11216 & 6472 & 9798 & 14298 & 19786 & 25459 & 29858 & 20.509 \\
\hline & & $\varepsilon^{(\mathbf{0})}(k)$ & 0 & 7220 & 5343 & 4166 & -1339 & 6934 & 1346 & \\
\hline & & $\Delta_{k}(\%)$ & 0 & \begin{tabular}{|l|}
52.732 \\
\end{tabular} & 35.290 & 22.563 & 7.259 & 21.406 & 4.313 & \\
\hline \multirow[t]{4}{*}{6} & Antalya & Actual & 24821 & 30602 & 31419 & 35451 & 34555 & 59478 & 62227 & \\
\hline & & Forecasted & 24821 & 12946 & 18979 & 26981 & 36724 & 47135 & 56140 & 22.571 \\
\hline & & $\varepsilon^{(\mathbf{0})}(\boldsymbol{k})$ & 0 & 17656 & 12440 & 8470 & -2169 & 12343 & 6087 & \\
\hline & & $\Delta_{k}(\%)$ & 0 & 57.696 & 39.593 & 23.893 & 6.276 & 20.753 & 9.783 & \\
\hline \multirow[t]{4}{*}{7} & Eskişehir & Actual & 9928 & \begin{tabular}{|l|}
11077 \\
\end{tabular} & 14006 & 17325 & 19422 & 21292 & 19921 & \\
\hline & & Forecasted & 9928 & 6827 & 10621 & 15239 & 19508 & 21630 & 20472 & 11.339 \\
\hline & & $\varepsilon^{(0)}(k)$ & 0 & 4250 & 3385 & 2086 & -86 & -338 & -551 & \\
\hline & & $\Delta_{k}(\%)$ & 0 & 38.364 & 24.170 & 12.042 & 0.445 & 1.586 & 2.766 & \\
\hline \multirow[t]{4}{*}{8} & Kayseri & Actual & 10615 & 13015 & 15873 & 19040 & 18581 & 27109 & 28375 & \\
\hline & & Forecasted & 10615 & 6343 & 9651 & 14046 & 19171 & 23994 & 26974 & 19.471 \\
\hline & & $\varepsilon^{(0)}(k)$ & 0 & 6672 & 6222 & 4994 & -590 & 3115 & 1401 & \\
\hline & & $\Delta_{k}(\%)$ & 0 & 51.268 & 39.196 & 26.228 & 3.176 & 11.491 & 4.938 & \\
\hline \multirow[t]{4}{*}{9} & Konya & Actual & 10102 & \begin{tabular}{|l|}
13963 \\
\end{tabular} & 14434 & 16838 & 17491 & 27724 & 29385 & \\
\hline & & Forecasted & 10102 & 5649 & 8486 & 12335 & 17100 & 22213 & 26539 & 22.756 \\
\hline & & $\varepsilon^{(\mathbf{0})}(k)$ & 0 & 8314 & 5948 & 4503 & 391 & 5511 & 2846 & \\
\hline & & $\Delta_{k}(\%)$ & 0 & 59.540 & 41.209 & 26.745 & 2.235 & 19.876 & 9.687 & \\
\hline \multirow[t]{4}{*}{10} & Adana & Actual & 9981 & 13057 & 14084 & 17412 & 15911 & 20928 & 20897 & \\
\hline & & Forecasted & 9981 & 6223 & 9440 & 13445 & 17524 & 20379 & 20779 & 17.346 \\
\hline & & $\varepsilon^{(0)}(k)$ & 0 & 6834 & 4644 & 3967 & -1613 & 549 & 118 & \\
\hline & & $\Delta_{k}(\%)$ & 0 & 52.339 & 32.973 & 22.783 & 10.140 & 2.622 & 0.562 & \\
\hline \multirow[t]{4}{*}{11} & Turkey & Actual & 427105 & 555184 & 607098 & 708275 & 701621 & 1157190 & 1165381 & \\
\hline & & Forecasted & 427105 & 243134 & 365983 & 530936 & 730380 & 934593 & 1091103 & 21.524 \\
\hline & & $\varepsilon^{(0)}(k)$ & 0 & 312050 & 241115 & 177339 & -28759 & 222597 & 74278 & \\
\hline & & $\Delta_{k}(\%)$ & 0 & 56.207 & 39.716 & 25.038 & 4.099 & 19.236 & 6.374 & \\
\hline
\end{tabular}


Table 7. Actual and forecasted house sales in NGVM (2008-2014)

\begin{tabular}{|c|c|c|c|c|c|c|c|c|c|c|}
\hline & \multirow{2}{*}{ Provinces } & \multicolumn{8}{|c|}{ House Sales Amount } & \multirow[t]{2}{*}{ MAPE (\%) } \\
\hline & & Years & 2008 & 2009 & 2010 & 2011 & 2012 & 2013 & 2014 & \\
\hline \multirow[t]{4}{*}{1} & Ankara & Actual & 87087 & 104285 & 106006 & 117908 & 106019 & 137773 & 131825 & \\
\hline & & Forecasted & 87087 & 96987 & 106149 & 114353 & 121482 & 127518 & 132519 & 4.672 \\
\hline & & $\varepsilon^{(1)}(k)$ & 0 & 7298 & -143 & 3555 & -15463 & 10255 & -694 & \\
\hline & & $\Delta_{k}(\%)$ & 0 & 6.999 & 0.135 & 3.015 & 14.585 & 7.443 & 0.526 & \\
\hline \multirow[t]{4}{*}{2} & İstanbul & Actual & 103503 & 140573 & 153897 & 169015 & 167110 & 234789 & 225454 & \\
\hline & & Forecasted & 103503 & 124963 & 147323 & \begin{tabular}{|l|}
169529 \\
\end{tabular} & 190553 & 209580 & 226106 & 5.819 \\
\hline & & $\varepsilon^{(1)}(k)$ & 0 & \begin{tabular}{|l|}
15610 \\
\end{tabular} & 6574 & -514 & -23443 & 25209 & -652 & \\
\hline & & $\Delta_{k}(\%)$ & 0 & 11.104 & 4.271 & 0.304 & 14.029 & 10.737 & 0.289 & \\
\hline \multirow[t]{4}{*}{3} & İmir & Actual & 26627 & 34828 & 39702 & 44876 & 46429 & 72421 & 71779 & \\
\hline & & Forecasted & 26227 & 32573 & 39358 & 46898 & 55036 & 63549 & 72165 & 6.168 \\
\hline & & $\varepsilon^{(1)}(k)$ & 0 & 2255 & 344 & -2022 & -8607 & 8872 & -386 & \\
\hline & & $\Delta_{k}(\%)$ & 0 & 6.474 & 0.867 & 4.505 & 18.539 & 12.251 & 0.538 & \\
\hline \multirow[t]{4}{*}{4} & Bursa & Actual & 10244 & 14879 & 19966 & 24092 & 24724 & 40894 & 42437 & \\
\hline & & Forecasted & 10244 & 13852 & 18344 & 23684 & 29695 & 36056 & 42367 & 6.974 \\
\hline & & $\varepsilon^{(1)}(k)$ & 0 & 1027 & 1622 & 408 & -4971 & 4838 & 70 & \\
\hline & & $\Delta_{k}(\%)$ & 0 & 6.902 & 8.123 & 1.692 & 20.105 & 11.830 & 0.165 & \\
\hline \multirow[t]{4}{*}{5} & Mersin & Actual & 11216 & 13692 & 15141 & 18464 & 18447 & 32393 & 31204 & \\
\hline & & Forecasted & 11216 & 13740 & 16676 & 20023 & 23753 & 27805 & 32088 & 9.241 \\
\hline & & $\varepsilon^{(1)}(k)$ & 0 & -48 & -1535 & -1559 & -5306 & 4588 & -884 & \\
\hline & & $\Delta_{k}(\%)$ & 0 & 0.350 & 10.136 & 8.442 & 28.762 & 14.163 & 2.833 & \\
\hline \multirow[t]{4}{*}{6} & Antalya & Actual & 24821 & 30602 & \begin{tabular}{|l|}
31419 \\
\end{tabular} & 35451 & 34555 & 59478 & 62227 & \\
\hline & & Forecasted & 24821 & 28688 & 33284 & 38792 & 45459 & 53630 & 63791 & 9.359 \\
\hline & & $\varepsilon^{(1)}(k)$ & 0 & 1914 & -1865 & -3341 & -10904 & 5848 & -1564 & \\
\hline & & $\Delta_{k}(\%)$ & 0 & 6.255 & 5.935 & 9.423 & 31.556 & 9.833 & 2.514 & \\
\hline \multirow[t]{4}{*}{7} & Eskişehir & Actual & 9928 & 11077 & 14006 & 17325 & 19422 & 21292 & 19921 & \\
\hline & & Forecasted & 9928 & 12561 & 15032 & 17119 & 18730 & 19891 & 20685 & 5.127 \\
\hline & & $\varepsilon^{(1)}(k)$ & 0 & -1484 & -1026 & 206 & 692 & 1401 & -764 & \\
\hline & & $\Delta_{k}(\%)$ & 0 & 13.398 & 7.324 & 1.191 & 3.563 & 6.582 & 3.834 & \\
\hline \multirow[t]{4}{*}{8} & Kayseri & Actual & 10615 & 13015 & 15873 & 19040 & 18581 & 27109 & 28375 & \\
\hline & & Forecasted & 10615 & 12892 & 15495 & 18405 & 21579 & 24947 & 28421 & 4.419 \\
\hline & & $\boldsymbol{\varepsilon}^{(\mathbf{1})}(\boldsymbol{k})$ & 0 & 123 & 378 & 635 & $\begin{array}{l}-2998 \\
\end{array}$ & 2162 & -46 & \\
\hline & & $\Delta_{k}(\%)$ & 0 & 0.944 & 2.381 & 3.335 & 16.132 & 7.975 & 0.163 & \\
\hline \multirow[t]{4}{*}{9} & Konya & Actual & 10102 & 13963 & 14434 & 16838 & 17491 & 27724 & 29385 & \\
\hline & & Forecasted & 10102 & 12217 & 14719 & 17655 & 21068 & 24991 & 29443 & 7.119 \\
\hline & & $\varepsilon^{(1)}(k)$ & 0 & 1746 & -285 & -817 & -3577 & 2733 & -58 & \\
\hline & & $\Delta_{k}(\%)$ & 0 & 12.507 & 1.972 & 4.852 & 20.449 & 9.859 & 0.197 & \\
\hline \multirow[t]{4}{*}{10} & Adana & Actual & 9981 & 13057 & 14084 & 17412 & 15911 & 20928 & 20897 & \\
\hline & & Forecasted & 9981 & 12093 & 14226 & 16258 & 18090 & 19661 & 20949 & 5.003 \\
\hline & & $\varepsilon^{(1)}(k)$ & 0 & 964 & -142 & 1154 & -2179 & 1267 & -52 & \\
\hline & & $\Delta_{k}(\%)$ & 0 & 7.386 & 1.006 & 6.626 & 13.697 & 6.056 & 0.251 & \\
\hline \multirow[t]{4}{*}{11} & Turkey & Actual & 427105 & 555184 & 607098 & 708275 & 701621 & 1157190 & 1165381 & \\
\hline & & Forecasted & 427105 & 515308 & \begin{tabular}{|l|}
617699 \\
\end{tabular} & 734908 & 866951 & 1013050 & 1171517 & 7.034 \\
\hline & & $\varepsilon^{(1)}(k)$ & 0 & 39876 & \begin{tabular}{|l|}
-10601 \\
\end{tabular} & -26633 & -165330 & 144140 & -6136 & \\
\hline & & $\Delta_{k}(\%)$ & 0 & 7.182 & 1.746 & 3.760 & 23.564 & 12.456 & 0.527 & \\
\hline
\end{tabular}

When tables were examined it was observed that MAPE values between forecasted values and actual values regarding ten provinces where house sales are most intensively performed were observed to be calculated for GM $(1,1)$ as $7.039 \%$, for GVM original data as $7.329 \%$, for GVM raw data as $19.364 \%$ and for NGVM as $6.390 \%$. NGVM, GM $(1,1)$ and GVM original data where mean absolute percentage error values are lowest are most reliable models for the study. On the other hand NGVM where MAPE value was determined to be lowest demonstrates a forecast reliability of $100 \%-6.390 \%$ $=93.610 \%$. 
When house sales data in ten provinces of Turkey where house sales activity is most intensive between 20082014 were examined NGVM, GM $(1,1)$ and GVM original data are most reliable models for the study. From this point of view NGVM where MAPE value was determined to be lowest demonstrates a forecast reliability of $100 \%-7.034 \%=$ $92.966 \%$. In terms of calculated mean absolute percentage error GVM original data gives much better results compared to GVM raw data and the fact that there is no significant difference between forecasted and actual values expresses the success of NGVM, GM $(1,1)$ and GVM original data so as to perform forecasting on chaotic data with a very low error ratio.

In figure 3, it is possible to see realized house sales values in all provinces of Turkey and the forecast values for 2008-2018 obtained from GM (1,1), GVM original data, GVM raw data and NGVM. In this direction, the forecasts obtained from the NGVM, GM $(1,1)$ and GV original data which have the lowest MAPE values shows that the house sales in Turkey will demonstrate an increasing trend between 2015 and 2018.

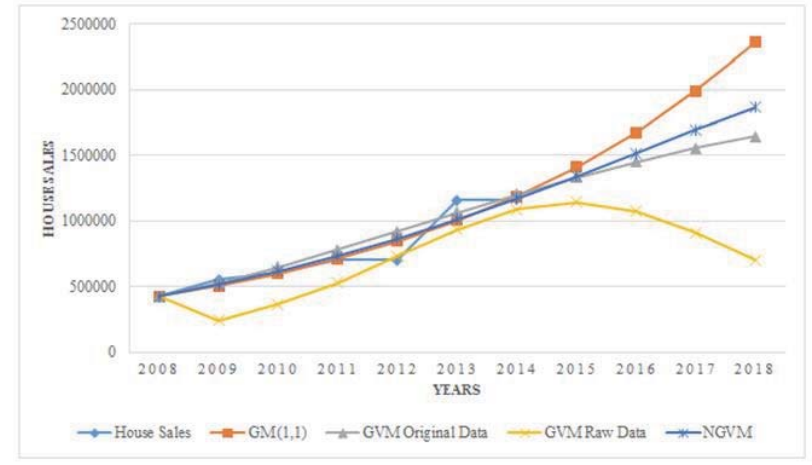

Figure 3. Actual values for all provinces in Turkey and forecasted values obtained from GM $(1,1)$, GVM original data, GVM raw data and NGVM

\section{Conclusions}

In this study, GM (1,1), GVM and NGVM were used in order to analyze the house sales quantity in Turkey between 2008 and 2014 and to make forecast for the future in light of this data. These forecasts were compared with the values realized between the same years so it was demonstrated that GM $(1,1)$, GVM and NGVM perform healthy forecasts in terms of obtained results and MAPE ratios. After the global crisis, starting from 2010, housing sector in Turkey was active. Together with the rapid growth in housing sector, which is the locomotive of the economical developments, Turkey's young and dynamic demographic structure is considered to support the demand towards housing market in incoming years. On the other hand urban conversion process which will further show its effect on the sector in incoming years and borrowing costs and stability in labor market which are most important factors affecting the demand of households are considered to have important contribution to development of sector.

Considering that the housing market in Turkey is directly affected mainly from demographic structure, prosperity and growth of the country, interest rates and regulations related with housing sector following and analysis of the indications related with the sector become more important. Forecasting the future in order to take proactive precautions against the possible problems is becoming obligatory for the sector. For these reasons GM $(1,1), \mathrm{GVM}$ and NGVM were used to demonstrate their reliability and the housing demand in Turkey between 2015 and 2018 was forecasted. As effective forecast models it was proved that GM $(1,1)$, GVM and NGVM can be used for the forecast of other indications related with the sector.

When literature is examined it is observed that there are no studies in Turkey related with housing demand performed by grey forecast, that GM $(1,1)$ is mostly used in studies related with demand forecast but that forecasts obtained from GVM original data, GVM raw data and NGVM were not comparatively incorporated to the studies together with $\mathrm{GM}(1,1)$.

In this study which was performed by GM $(1,1)$, GVM original data, GVM raw data and NGVM, forecasts were made by starting from single data set. In the literature many intuitional and stochastic models are used together with GM. In future stages of the study, above mentioned models will be used and instead of using single data set the factors 
affecting the residence demand will be determined and forecasts will be developed by using these models together with GM $(1, n)$ and / or fuzzy grey forecast models.

\section{References}

Deng J.L., (1982): "Control Problems of Grey Systems", Systems \& Control Letters, Pp 288-294.

Deng J.L., (2000): "The Grey System Theory and Application", Kao-Li Book Company, (1 st ed.)

Liu,S. and Lin, Y., (2006): "Grey Information: Theory and Practical Applications", Springer, Pp 11-21.

Hsu, Li-Chang, (2003): "Applying the Grey Prediction Model to the Global Integrated Circuit Industry", Technological Forecasting \& Social Change, 70, Pp 563-574.

Yao, Albert W. L. (2003): Chi, S. C. and Chen, J. H., "An Improved Grey-Based Approach for Electricity Demand Forecasting", Electric Power Systems Research, 67, Pp 217-224.

Akay, Diyar and Atak, Mehmet, (2007): "Grey Prediction with Rolling Mechanism for Electricity Demand Forecasting of Turkey", Energy, 32, Pp 1670-1675.

Kung, Chaang-Yung, Chang, Cheng-Ping, (2004): "Application of Grey Prediction Model on China Automobile Industry", The Journal of Grey System 2, Pp 147-154.

Kayacan, Erdal; Ulutas, Barış and Kaynak, Okyay, (2010): "Grey System Theory - Based Models in Time Series Prediction", Expert Systems with Applications, 37, Pp 1784-1789.

Askari, Mehdi and Askari, Hadi, (2011): "Time Series Grey System Prediction - Based Models: Gold Price Forecasting", Trends in Applied Science Research, 6, Pp 1287-1292.

Wang, Jianhui, (2007): "The Application of the Grey Verhulst Model for Business Valuation", The Journal of Grey System 2, Pp 159-166.

Wang, Zhengxin; Dang, Yaoguo and Wang, Yemei, (2007): "A New Grey Verhulst Model and Its Application", IEEE International Conference on Grey Systems and Intelligent Services, Pp 571-574.

Kordnoori, Shaghayegh; Mostafaei, Hamidreza and Kordnoori, Shirin, (2014): "The Application of Fourier Residual Grey Verhulst and Grey Markov Model in Analyzing the Global ICT Development", Hyperion Economic Journal.

Wang, Yuhong; Tang, Jianrong and Cao, Wenbin, (2012): "Grey Prediction Model - Based Food Security Early Warning Prediction", Grey Systems: Theory and Application, 2, Pp 13-23.

Chiang, J.S., Wu, P.L., Ciang, S.D., Chang, T.J., Chang, S.T. and Wen, K.L., (1998): "Introduction of Grey System Theory", GAO-Li Publication.

Lewis, C.D., (1982): "Industrial and Business Forecasting Methods", London: Butterworth Scientific, 1982.

Turkish statistical institute (TUIK), House Sales Statistics (Internet), http://www.tuik.gov.tr/PreTablo.do?alt_id=1056, Assessed on July $15^{\text {th }}, 2015$ 